\title{
O processo coletivo estrutural como forma de remediar a normatividade simbólica
}

\section{da educação ambiental}

\author{
The structural class action as a way to remedy the symbolic normativity of environmental \\ education
}

La acción de clase estructural como forma de remediar la normatividad simbólica de la educación ambiental

\author{
Ana Luíza Rocha Barros \\ ORCID: https://orcid.org/0000-0003-0363-6525 \\ Escola Superior Dom Helder Câmara, Brasil \\ E-mail: analurb.98@gmail.com \\ Larissa Martins Alves dos Santos \\ ORCID: https://orcid.org/0000-0002-3609-2889 \\ Escola Superior Dom Helder Câmara, Brasil \\ E-mail: lamartins2013@gmail.com \\ Magno Federici Gomes \\ ORCID: https://orcid.org/0000-0002-4711-5310 \\ Escola Superior Dom Helder Câmara, Brasil \\ E-mail: magnofederici@gmail.com
}

\begin{abstract}
Resumo
A falta de consciência e formação crítica ambiental é um desafio mundial. O presente artigo objetiva estudar o processo estrutural de interesse público como forma de implementar uma efetiva educação ambiental, ante o poder e dever de atuação Estatal e social do meio ambiente. Para abordagem, utilizar-se-á o método hipotético-dedutivo, a pesquisa qualitativa exploratória baseada em levantamento bibliográfico e documental. Verifica-se como resultado que o processo estrutural de interesse público pode ser instrumento hábil à efetivação da educação ambiental, ao instar o Poder Público, por meio de medidas estruturantes, a inseri-la como disciplina obrigatória no ensino básico brasileiro.
\end{abstract}

Palavras-chave: Educação ambiental; Efetividade; Processo estrutural.

\begin{abstract}
The lack of environmental awareness and critical education is a worldwide challenge. The present article aims to study the structural process of public interest as a way to implement an effective environmental education, before the power and duty of State and social performance of the environment. For the approach, the hypothetical-deductive method will be used, the qualitative exploratory research based on bibliographic and documental survey. It is verified as a result that the structural process of public interest can be a capable instrument for the effectiveness of environmental education, by urging the Public Power, through structuring measures, to insert it as a mandatory subject in Brazilian basic education.
\end{abstract}

Keywords: Environmental education; Effectiveness; Structural process.

\section{Resumen}

La falta de concienciación y educación ambiental crítica es un reto mundial. El presente artículo tiene como objetivo estudiar el proceso estructural del interés público como forma de implementar una educación ambiental efectiva, ante el poder y el deber del Estado y la actuación social del medio ambiente. Para su abordaje, se utilizará el método hipotético-deductivo, investigación cualitativa exploratoria basada en el relevamiento bibliográfico y documental. Se verifica como resultado que el proceso estructural de interés público puede ser un instrumento hábil para la eficacia de la educación ambiental, al instar al Poder Público, por medio de medidas estructurales, a insertarla como disciplina obligatoria en la enseñanza básica brasileña.

Palabras clave: Educación ambiental; Eficacia; Proceso estructural. 


\section{Introdução}

O consumo exacerbado dos recursos da natureza, somada à ausência de senso crítico social de responsabilidade ambiental, afeta o contexto global. Diante da afirmativa, questiona-se: como promover a modificação de mudanças de paradigmas de modo a conservar e defender o meio ambiente?

Apesar da existência de direitos inerentes às questões ambientais, convive-se em uma sociedade cujos interesses econômicos se sobrepõem aos demais, prejudicando o equilíbrio sociocultural e ambiental dos Estados, e acarretando a fome e a pobreza na população mundial, entre outras circunstâncias negativas para o meio ambiente.

Nesse diapasão é fundamental destacar a relevância pela transformação de atitudes e reflexões críticas, como iniciativa fundamental para a formação de uma sociedade altruísta e filantrópica.

O presente artigo visa analisar a atuação do poder e dever do Estado e da sociedade enquanto titulares constitucionalmente responsáveis por assegurar ao meio ambiente o direito de ser ecologicamente estável. Na abordagem, estudar-se-á normas e preceitos norteadores do ordenamento pátrio, que destacam a importância da promoção educacional ambiental, a fim de se formar uma sociedade consciente, como instrumento efetivo a estimular o conhecimento e análise crítica das questões ambientais, em busca de minimizar as violações ocorrentes.

Entretanto, ao se constatar que apesar da importância da educação ambiental, esta vem se perfazendo enquanto uma norma meramente simbólica, o artigo propõe como problema de pesquisa compreender se o processo estrutural pode solucionar os problemas relacionados com a efetividade da educação ambiental

Em um primeiro momento, far-se-á neste artigo, uma breve introdução da normatividade simbólica da educação ambiental e suas concepções. Por conseguinte, estudar-se-á o processo coletivo estrutural de interesse público, abordando suas origens, conceitos, pressupostos e interações. Por fim, abordar-se-á o processo estrutural de caráter público, como possível mecanismo procedimental apto a solucionar parte dos problemas relacionados com a normatividade simbólica da educação ambiental, de modo a afastar sua simbologia e alcançar sua efetividade prática no ensino básico brasileiro.

\section{Metodologia}

Para cumprir os objetivos mencionados em linhas volvidas, se baseando em (Severino, 2007) e (Silva, 2006) a pesquisa se perfaz, na vertente hipotético-dedutivo, de abordagem qualitativa, pelo fato da defesa do meio ambiente e a educação ambiental ser um instrumento de fenômeno social atual. A pesquisa é ainda exploratória, conforme classificação de (Antônio Carlos Gil, 2009, p. 41-42), uma vez pretender com o presente estudo, investigar, através da análise documental, doutrinária e legislativa, a possibilidade do processo estrutural se figurar como mecanismo hábil a remediar a normatividade simbólica da educação ambiental.

\section{Resultados e Discussão}

\subsection{A análise do poder e de dever de atuação estatal e da sociedade na proteção do meio ambiente}

No cenário atual, a preocupação com o consumo exorbitante dos bens naturais e a carência na preservação e defesa do meio ambiente é um problema mundial. Quando citamos alguns dos maiores desastres ambientais ocorridos pelo mundo, como a explosão de Chernobyl, na Ucrânia em 1986, o acidente nuclear de Fukushima, no Japão em 2011, a explosão que armazenava nitrato de amônio em Beirute, no Líbano em 2020, o acidente radioativo em Goiânia, no ano de 1987, e o rompimento das barragens de Mariana em 2015 e de Brumadinho em 2019 no Estado de Minas Gerais, demonstra-se claro a falta de responsabilidade socioambiental da sociedade. 
De acordo com Aguirre "A preocupação com o ambiente natural vem, paulatinamente, através das últimas décadas, aumentando de forma intensa. Reflexo da perspectiva iminente de escassez de recursos naturais que se avizinha para a humanidade" (Aguirre, 2004, p. 68).

Diante disso, é evidente a vulnerável consciência do ser humano em se preocupar com os assuntos referentes a ambiência. Assim a Conferência de Estocolmo, em 1972, promovida pela Organização das Nações Unidas (ONU), realizou o primeiro evento que demonstrou a importância em discutir questões ambientais no âmbito global.

A CF/88, traz a tutela jurídica ambiental, seguindo uma tendência universal, em caráter normativo e obrigatório, a qual dispõe no art. 225 que: "todos têm direito ao meio ambiente ecologicamente equilibrado, bem de uso comum do povo e essencial à sadia qualidade de vida, impondo-se ao poder público e à coletividade o dever de defendê-lo e preservá-lo para as presentes e futuras gerações" (Brasil, 1998).

É imprescindível que, apesar do avanço tecnológico, a preocupação ambiental seja um dos assuntos que deve ser tratado com maior relevância, uma vez que as agressões e explorações desenfreadas dos recursos naturais só aumentam.

A Lei n. ${ }^{\circ}$ 6.938/91 denominada Política Nacional do Meio Ambiente esclarece no art. $2^{\circ}$ que: "o objetivo da preservação, melhoria e recuperação da qualidade ambiental propícia à vida, visando assegurar, no País, condições ao desenvolvimento socioeconômico, aos interesses da segurança nacional e à proteção da dignidade da vida humana" (Brasil, 1991).

Consagra ainda, a referida lei, o Princípio da Precaução, o qual pretende, preservar o equilíbrio ecológico e os atributos do meio ambiente, bem como promover critérios de normas relativas ao emprego dos recursos naturais.

Salienta-se que, em 1992, a Conferência das Nações Unidas, no Rio de Janeiro, denominada Declaração ECO 92, declarou os princípios e a importância da participação da sociedade e do Estado, relativos às questões ambientais e ao desenvolvimento sustentável, determinando no $12^{\circ}$ princípio que: "Os Estados devem cooperar para o estabelecimento de um sistema econômico internacional aberto e favorável, propício ao crescimento econômico e ao desenvolvimento sustentável em todos os países [...] ” (Organização das Nações Unidas, 1992).

Dessa forma, a retomada da sociedade de um novo pensamento ecologicamente sustentável, nunca foi tão importante, sendo necessário a participação efetiva e conjunta do poder e dever da atuação do estado e da sociedade, visando possibilitar o tratamento adequado para os problemas ambientais e evitar degradações ao meio ambiente. Assim:

Se o povo não reivindicar seus direitos em matéria ambiental, o Estado certamente entenderá que esta não é uma área que necessita de grandes investimentos, tornando-se omisso na concretização do direito ao meio ambiente ecologicamente equilibrado, ignorando a previsão constitucional de assegurá-lo. (Bonifácio \& Santos, 2020, p. 193).

Embora existam leis relativas à preservação, proteção e defesa ambiental, a realidade da sociedade em que se vive é meramente capitalista, causando inconformidades, no sentido econômico, social e cultural dos Estados.

Assim, a Lei n. ${ }^{\circ}$ 9.605/98, chamada Lei de Crimes Ambientais, regulamenta os atos prejudiciais ao meio ambiente, com sanções na esfera penal e administrativa que esclarece no $2^{\circ}$ art. que: "Quem, de qualquer forma, concorre para a prática dos crimes previstos nesta Lei, incide nas penas a estes cominadas, na medida da sua culpabilidade, [...] que, sabendo da conduta criminosa de outrem, deixar de impedir a sua prática, quando podia agir para evitá-la" (Brasil, 1998).

Nesse caso, cumpre lembrar que o Poder Público tem responsabilidade e o compromisso de resguardar e proteger o meio ambiente contra qualquer dano ou agressão, caso contrário, também poderá ser responsabilizado.

Perante o exposto, a CF/88, dispõe no art. $225 \S 1^{\circ}$ que: 
Para assegurar a efetividade desse direito, incumbe ao poder público: I - preservar e restaurar os processos ecológicos essenciais e prover o manejo ecológico das espécies e ecossistemas; [...] III - definir, em todas as unidades da Federação, espaços territoriais e seus componentes a serem especialmente protegidos. (Brasil, 1998).

Diante disso, o Estado tem o dever de ter uma atuação benéfica, reconhecendo a importância de promover políticas públicas para a concretude de direitos com conteúdo de proteção e amparo ambiental e a promoção de mudanças de hábitos, pensamentos e atitudes, para que a sociedade se torne ecologicamente equilibrada, sustentável e ética.

A participação é o ponto de partida para a proteção efetiva do meio ambiente. Ninguém vai salvar o planeta sozinho, pois somente o engajamento de todos na gestão dos recursos naturais e o potencial ecológico do planeta é que garantirá um projeto civilizatório mais promissor para o futuro da humanidade. (Brasil, et al., 2016, p. 14).

Percebe-se, dessa feita, que a educação ambiental (EA) é o sustento de todas as políticas ambientais, tornando-se o instrumento para promover uma nova concepção de agir e pensar, a fim de conscientizar a população da responsabilidade e do cuidado com o meio ambiente.

[...] a educação ambiental pode constituir espaço privilegiado de construção de conhecimentos sobre o que se produz na interação homem-sociedade-natureza e, assim, criar condições para uma nova relação entre os seres vivos. (Demoly \& Santos, 2018, p. 3).

Por isso, o espaço escolar é o local para se debater e questionar ideias, e opiniões sobre os assuntos ambientais, na construção de uma mudança individual, para que possa se tornar coletiva.

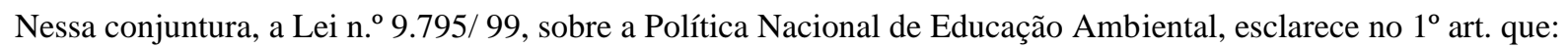

Entendem-se por educação ambiental os processos por meio dos quais o indivíduo e a coletividade constroem valores sociais, conhecimentos, habilidades, atitudes e competências voltadas para a conservação do meio ambiente, bem de uso comum do povo, essencial à sadia qualidade de vida e sua sustentabilidade. (Brasil, 1999).

Importa compreender que citar a EA, resgata um direito fundamental garantido, titulado educação, de natureza social, imprescindível para crescimento intelectual e pessoal de aprendizagem de todos. A CF/88 no artigo 205 diz: “A educação, direito de todos e dever do Estado e da família, será promovida e incentivada com a colaboração da sociedade, visando ao pleno desenvolvimento da pessoa, seu preparo para o exercício da cidadania e sua qualificação para o trabalho" (Brasil, 1988).

A educação ambiental é um caminho transformador na obtenção de uma sociedade participativa, que deve ser iniciada no ensino básico, como proposta de oferecer informações adequadas e coerentes.

\subsection{A normatividade simbólica da educação ambiental}

Diante do crescimento econômico associado ao capitalismo e o consumismo, o ser humano e grande parte das atividades empreendedoras demonstram a falta de responsabilidade socioambiental com o meio ambiente.

Uma das ferramentas para ressignificar o comportamento do ser humano e construir uma consciência analítica e crítica é a educação ambiental, que corrobora para a mudança de paradigmas. "A educação ambiental é, pois, um instrumento hábil para disseminar a necessidade em se preservar o meio ambiente alertando a sociedade dos riscos em, num futuro não muito distante, [...] consequentemente, extinguir a própria espécie humana" (Carvalho \& Reis, 2017, p.24).

A mínima compreensão da importância de preservá-lo, pode acarretar no futuro, a escassez dos recursos naturais. Segundo a Lei n ${ }^{\circ}$ 9.795/99, que dispõe sobre a Política Nacional da Educação Ambiental: “a educação ambiental é um componente essencial e permanente da educação nacional, devendo estar presente, de forma articulada, em todos os níveis e modalidades do processo educativo, em caráter formal e não formal” (Brasil, 1999). 
Nesse sentido, o Direito Ambiental enfrenta um impasse, que consiste em reeducar o pensamento crítico e atitude ativa e protetora da sociedade em benefício da preservação do meio ambiente e de sua própria espécie.

Não é demais evidenciar que o direito à educação de qualidade é ferramenta indispensável no processo de evolução humana, e tende a contribuir significativamente com o papel do desenvolvimento das dimensões da sustentabilidade que também é um processo evolutivo a ser alcançado pela humanidade. (Gomes \& Ferreira, 2017, p. 99).

Que por meio da educação, poderá evitar o uso excessivo e degradação dos recursos advindos da natureza como a fauna e flora em relação às atividades humanas. Nesse viés, a CF/88, tornou a EA obrigatória, a ser promovida nos níveis de ensino, de acordo com o art. 225, $\S 1^{\circ}$ "Para assegurar a efetividade desse direito, incumbe ao poder público: [...] VI promover a educação ambiental em todos os níveis de ensino e a conscientização pública para a preservação do meio ambiente" (Brasil, 1988). Uma vez que a reação do meio ambiente advinda de uma ação irresponsável do ser humano, evidencia sua supremacia e faz que os indivíduos sofram as consequências.

Importa observar que a Resolução ${ }^{\circ}{ }^{2}$, de 15 de junho de 2012, expedida pelo Conselho Nacional de Educação (CNE), estabelece as Diretrizes Curriculares Nacionais para a educação ambiental serem observadas pelos sistemas de ensino e suas instituições de educação básica e de educação superior, orientando o disposto Lei nº 9.795 de 1999 (Brasil, 2012).

Diante do exposto, surge a importância do fortalecimento da relação entre o ser humano e meio ambiente, para atingir todos os níveis da sociedade. "Promover a educação ambiental é, portanto, tarefa de todas as pessoas lúcidas, responsáveis e de boa-vontade. Nesse sentido, um dos grandes desafios para os educadores ambientais é resgatar e desenvolver valores e comportamentos [...]” (Linhares \& Piemonte, 2010, p. 109).

A educação ambiental tem como característica a transversalidade, ou seja, pode suceder-se em todas as disciplinas dos níveis de ensino, como perspectiva educativa interdisciplinar. Assim, a Lei 6.938/81, dispõe sobre a Política Nacional do Meio Ambiente, que esclarece como princípio: "a educação ambiental a todos os níveis de ensino, inclusive da comunidade objetivando capacitá-la para a participação ativa na defesa do meio ambiente” (Brasil, 1981).

Diante disso a EA é promovida em diferentes áreas de conhecimento, com estudos teóricos e práticos, resultando em um grande avanço para a construção da concepção ética ambiental, porém, somente a transversalidade não resolverá os problemas ambientais. "A inclusão da educação ambiental no currículo não é feita nem através de mais um assunto, nem através de uma cadeira, nem através de uma disciplina ou ações isoladas, não inscritas dentro de um processo sequencial e permanente de formação" (Escorihuela, et al., 2019, p. 240)1.

Apesar da educação ambiental promover o papel de estimular o processo de conscientização dos cidadãos por meio de mudança de hábitos e comportamentos de proteção ao meio ambiente, ainda questiona-se sua efetividade. Se faz necessário buscar mecanismos mais incisivos de aplicabilidade, como a proposta de inserir os assuntos ambientais como disciplina obrigatória nos parâmetros curriculares do ensino básico, sendo que o processo estrutural de interesse público pode se configurar como instrumento hábil a instar o Estado a implementar a política pública em comento.

\subsection{O processo coletivo estrutural como forma de se implementar uma efetiva educação ambiental}

Antes de se adentrar na análise do processo coletivo estrutural de interesse público, como instrumento hábil a instar o Poder Público a vincular e implementar a educação ambiental como disciplina específica obrigatória no ensino básico brasileiro, necessário introduzir e compreender o processo estrutural e o processo de interesse público, como institutos independentes e por vezes sobrepostos, sendo o que passa a demonstrar.

${ }^{1}$ Tradução livre: La inclusión de la educación ambiental en el currículo no se hace ni a través de una asignatura más, ni a través de una cátedra, ni a través de una disciplina o acciones aisladas, no inscritas dentro de un proceso formativo secuencial y permanente (escorihuela, et al., 2019, p.240) 


\subsubsection{O processo coletivo estrutural de interesse público}

Fenômeno, pesquisado há mais uma década por doutrinadores brasileiros, como Arenhart, Jobim, Zanetti, entre tantos outros, os chamados processos estruturais advêm, não de um instituto definido e positivado no ordenamento processual pátrio, mas sim, de situações litigiosas fáticas que, ao serem levadas ao Poder Judiciário, os desencadeará.

A terminologia structural litigation foi adotada pelo norte-americano Owen Fiss em 1979, ao analisar casos paradigmáticos como o Brown vs Board of Education ${ }^{2}$, que ocorreu na cidade americana de Topeka/Kansas, e que fora apreciado pela Suprema Corte do país em 1954. Ao analisar o caso em comento, palco de segregação racial e violação sistémica a direitos fundamentais, como o da igualdade, constitucionalmente garantido, a referida Corte assumira uma postura um tanto quanto inovadora e ativista: ao proferir a decisão, adotou uma série de ações coordenadas que deveriam ser assumidas pelo Estado Americano, a fim de preparar as escolas públicas, e suas equipes de profissionais e alunos a receberem uma criança negra, em uma instituição até então destinada apenas para brancos, sem que ela sofresse qualquer discriminação.

Desta forma, nos dizeres de Fiss, o processo estrutural se figura como "o instrumento formal, por intermédio do qual o Judiciário busca reorganizar instituições burocráticas para que funcionem de acordo com a Constituição” (FISS, 1993, p. 965, tradução nossa ${ }^{3}$ ). Em complemento à conceituação acima sedimentada, (Vitorelli, 2018, p.08) disserta poder derivar essa burocratização de uma prática pública e/ou privada cuja ação ou omissão gera um estado de violação generalizada, da qual se deriva um litígio estrutural.

Compilando os ensinamentos de Vitorelli aos lecionados por (Didier, et al., 2020, p.02), todo processo estrutural origina-se, portanto, de um litígio/problema estrutural, o qual possui como razão não necessariamente condutas ilícitas, mas condutas que geram um estado de coisas inconstitucional, desconformes aos dizeres e preceitos da constituição, que deverá ser posto em conformidade mediante um procedimento adequado, participativo e longínquo de execução ante a complexidade das questões que o enseja. Neste mesmo sentido, Verbic reflete que “a principal característica destes processos judiciais, é que versam sobre questões extremamente relacionadas com diferentes tipos de políticas públicas e derivam da imposição de ordens complexas, tanto para a definição de seus contornos quanto para sua execução" (Verbic, 2013, p.02) ${ }^{4}$.

Indo ao encontro da ideia abarcada pelos processos estruturais, porém os precedendo, Chayes, também professor da Universidade de Havard, assim como Fiss, a partir de 1976, passou a desenvolver sua análise e conceituação dos denominados processos de interesse público. Estes se diferem daqueles uma vez pretenderem não necessariamente reestruturar um estado desconforme já instaurado, mas sim, efetivar, por meio do reforço da atividade jurisdicional, um direito já garantido pela Carta Magna, bem como legislações infra, que por vezes não é ou não está sendo, devidamente cumprido pelas políticas estatais.

Neste ínterim, descreve Vitorelli:

[...] Public Law Litigation é uma expressão cunhada por Abrahan Chayes, em 1976, para descrever um fenômeno que, na sua visão, não vem desde Brown, mas do século XIX: o aumento do número de leis destinadas não a resolver um conflito pretérito, bilateral, existente entre particulares, mas a regular e modificar arranjos sociais e econômicos, para o futuro. Em outras palavras, a decisão judicial deixa de pretender remediar o ilícito pretérito, como tradicionalmente ocorre, para buscar ajustar o comportamento futuro do réu. Isso gera a necessidade de um regime de execução prolongado, em vez de uma transferência instantânea de patrimônio. O processo se afasta, com isso, de seu perfil clássico. Além disso, litígios de interesse público, na visão de Chayes, incidem sobre "uma lesão relativa à operação de uma política pública (Vitorelli, 2018, p. 12-13).

\footnotetext{
${ }^{3}$ Tradução livre de: "The formal medium through which the judiciary seeks to reorganize ongoing bureaucratic organizations so as to bring them into conformity with the Constitution" (Fiss, 1993, p. 965).

${ }^{4}$ Tradução livre: “[...] La principal característica de estos procesos judiciales, como veremos, es que versan sobre cuestiones estrechamente relacionadas con distintos tipos de políticas públicas y derivan en la imposición de órdenes complejas, tanto en lo que hace a la definición de sus contornos como en cuanto a su ejecución. [...]" (Verbic, 2013, p. 02).
} 
Dos ensinamentos acima colacionados, é possível perceber que embora os processos estruturais e os de interesse público sejam institutos independentes e originam-se de fontes acadêmicas diversas, ambos se sedimentam em pontos comuns. Possuem como escopo a mesma finalidade: instar uma instituição, seja privada ou necessariamente pública, como no caso dos litígios de Interesse Público (IP), a adotar posturas que objetivam alcançar um estado ideal de coisas emanado do ordenamento constitucional pátrio, seja visando, respectivamente, a reestruturar um estado de ilicitude já instaurado e/ou ajustar uma prática do Estado réu, a fim de se evitar futuras violações.

Embora independentes, em casos característicos e pontuais ambos os institutos poderão se sobrepor. Em que pese os litígios de IP, não se perfaçam como regra em procedimentos coletivos, quem dirá estruturais, por vezes assim serão. Possível se vislumbrar a hipótese de uma situação fática de desconformidade, que parte da omissão estatal de se implementar uma efetiva política pública que avance em direção a um direito fundamental, constitucionalmente garantido, e que o Poder Público ainda não esteja aparelhado para tal feito. Neste caso deverá o poder judicante, em conjunto com os envolvidos na causa, se reportar às decisões e medidas estruturantes, a fim de se implementar a política perseguida de forma gradual e orientada. Sobre o tema, destrincha Vitorelli:

Litígios de interesse público podem ser resolvidos na via do processo individual, mediante criação de um precedente obrigatório, na via do controle abstrato de constitucionalidade ou por intermédio de processos coletivos, estruturais ou não. Enquanto isto, todo processo estrutural é um processo coletivo, qualquer processo pode ser de interesse público, desde que se busque, por seu intermédio, a implementação de direitos que estão sob responsabilidade do Estado, não apenas para as partes, mas para todos os indivíduos que integram a sociedade de destinatários daquela prestação (Vitorelli, 2018, p. 12).

Desta forma, entende-se por processo coletivo estrutural de caráter público, aquele que, ajuizado por legitimados ativos, com amplo espectro de representação e atuação da sociedade civil interessada, visa, através do impulsionamento e gerenciamento do Poder Judiciário, compelir o Poder Público a implementar ou aperfeiçoar uma política pública que traduza e efetive um direito fundamental determinado pela CF/88. Embora o tema gere polêmicas discussões sobre o ativismo judicial, (Zaneti Jr, 2019, p.417), atenta que as decisões oriundas de tais procedimentos, se voltam a implementar "a legislação e em alguns casos a própria Constituição", não havendo que se falar em ativismo judicial, mas tão somente ativismo da lei e da Constituição.

A partir do acima exposto, vale explicitar que procedimentos desta natureza não tramitam sob as características tradicionais do processo civil, mas sim sob características próprias e devidas à complexidade do objeto que se tutela. Ao contrário de uma lide binária, linear, combativa, meramente patrimonial, e de um Estado judicante que por meio de uma única decisão terminativa julgará o mérito e extinguirá o feito, estar-se-á diante de uma lide multipolar, alinear, cooperativa, em que o juízo, assumindo uma postura ativa de gerenciamento dos diversos interesses, deverá impulsionar as propostas dos envolvidos de implementação e cumprimento da política discutida para, por meio de medidas e planos estruturantes, se alcançar de forma prospectiva o mérito da litigância.

Partindo dos pressupostos aqui tratados e alavancando-se da situação fática hipotetizada no sétimo parágrafo deste item, se avança a analisar o processo coletivo estrutural de interesse público como instrumento apto a vincular e implementar a educação ambiental no currículo da educação básica brasileira, como disciplina específica da matriz curricular, a fim de se garantir o direito fundamental ao meio ambiente ecologicamente equilibrado, previsto pelo art. 225 da CF/88. 


\subsubsection{O processo estrutural como forma de se vincular e implementar a educação ambiental como disciplina específica} na educação básica brasileira

Como explicitado nos capítulos iniciais a educação ambiental, nos termos da CF/88, mais precisamente no inciso VI $\S$ $1^{\circ}$ do art. 225, se perfaz como uma incumbência do Poder Público, o qual deverá promovê-la em todos os níveis de ensino de forma a sedimentar consciência e participação pública que vise alcançar e garantir o direito fundamental ao meio ambiente ecologicamente equilibrado.

Ao ser dissecada pela Lei n. ${ }^{\circ}$ 9.795/99, Decreto n. ${ }^{\circ}$ 4.281/2002, e ainda Resolução n. ${ }^{\circ} 2$ de 2012 do CNE, a educação ambiental, ao ser assegurada pela Carta Magna de forma ampla e norteadora, ao contrário de ser regulamentada em seu grau máximo, por opção do legislador, foi prevista e vem sendo implementada em grau mínimo, conforme reflexão, ao se valer o Poder Público de "programas e projetos tímidos ou insuficientes de educação ambiental" (Carvalho \& Gomes, 2016, p. 21).

A timidez se faz evidente aos olhos, ao analisar a Seção II da legislação ordinária acima mencionada, que em que pese em um primeiro momento preveja $\mathrm{EA}^{5}$ formal, como uma obrigatoriedade nas bases curriculares de ensino de instituições públicas e privadas, no $\S 1^{\circ}$ do mesmo dispositivo retroage, alegando não dever ser, entretanto, implementada como disciplina específica.

Nesta linha, a EA preceito constitucional que visa assegurar o direito fundamental do meio ambiente ecologicamente equilibrado, passa a se materializar nas escolas de ensino básico, não em uma disciplina isolada, ministrada por profissionais com habilidade e técnica suficiente para tratar da temática suprassuma, mas sim, de modo transversal, que nos dizeres de Guedes (2012, p.87), não estará ligada a nenhuma matéria particular, podendo-se considerar comum a todas.

A criação da disciplina específica em comento é facultada pelo $\S 2^{\circ}$ do art. 10, resumidamente, apenas aos cursos de pós-graduação e extensão, o que na visão dos autores, promove a elitização da consciência crítica e discussão ambiental, considerando estimar-se, de acordo com a Pesquisa Nacional por Amostra de Domicílios (PNAD) contínua 2018, que apenas $13.7 \%$ da população brasileira tiveram acesso ao curso superior. Desta forma, estender a previsão da disciplina específica ao ensino básico, indo além, vinculando-a como obrigatória e não meramente facultativa, seria democratizar o conhecimento, tendo em vista, que pela mesma fonte acima mencionada, o número daqueles que concluíram o ensino básico é mais abrangente, qual seja, $46.4 \%$.

Sobre o até aqui exposto, pondera-se que, o intuito da proposição que se pretende construir, não é desobrigar a EA formal diluída em todas as matérias da matriz curricular do ensino básico, pois compreende-se a importância desta transversalidade. É, porém, reforçá-la em uma matéria específica, tendo em vista que mesmo a legislação (art. 11), dissertar deve receber os professores em atividade, capacitação para alcançar os princípios e objetivos da Política Nacional da EA em suas respectivas áreas de atuação, na prática não é o que ocorre de forma latente:

Sobretudo considerando-se a complexidade científica e técnica das questões ambientais e da gravidade do atual estágio de degradação ambiental e dos riscos ambientais. Nem todos os docentes estão aptos teórica, metodológica e pedagogicamente a trabalhar com os temas ambientais, em sala de aula ou em atividades complementares (Steinmetz, 2009, p. 6).

Valendo-se da menção feita pela citação supra ao atual cenário de graves degradações e riscos ambientais, reafirma-se a necessidade de se repensar e vincular a EA em todas as suas potencialidades como instrumento apto a despertar e capacitar a coletividade na defesa crítica e ativa ao meio ambiente, tanto em face do Poder Público, em suas ações que por vezes pode o violar, quanto junto a este, uma vez não ser possível “acreditar - ou mesmo desejar - que o Estado seja capaz de exercer

${ }^{5}$ EA: Educação Ambiental. 
controle absoluto sobre todas as atividades que, direta ou indiretamente, possam alterar negativamente a qualidade ambiental [...]" ( Antunes, 2012, p. 237).

Passando a dialogar com a temática abarcadas no item 3.1 deste capítulo, inicia-se dissertando que os processos estruturais a nível brasileiro, foram e vem sendo comumente utilizados em casos paradigmas que buscam a reparação de um grave dano causado ao meio ambiente. Possível citar, como exemplo, a conhecida ACP do Carvão decorrente da explosão de uma mina na cidade de Criciúma/SC, que além de interromper a vida de 31 mineiros, afetou os recursos hídricos da região. Ainda, menciona-se pelos rompimentos das barragens de rejeitos no Estado de Minas Gerais, respectivamente em Mariana e Brumadinho, cujas ações civis públicas galgam esforços para indenizar vítimas e recuperar todo o ecossistema das diversas regiões atingidas.

Dos casos referenciados, vislumbra-se a instrumentalização dos procedimentos estruturais como mecanismo processual reparador e instituidor de políticas preventivas após os danos ambientais já terem se instaurado. Entretanto, por que não se valer dos processos estruturais, mais precisamente os de interesse público, como mecanismo que implemente uma política remediadora da causa desses danos?

A EA formal em sua modalidade transversal, em conjunto com a não-formal, já vem desempenhando, mesmo que não na intensidade esperada e devida, a conscientização populacional sob aspectos ambientais tangentes ao cotidiano, como a poluição, desmatamento, reciclagem. Todavia, quando se está diante de crimes/desastres ambientais, como os que o país vem incessantemente presenciando, ocasionados pela atuação de interesses econômicos e empreendimentos predadores, é preciso conclamar a população, e a ela confiar capacidade técnica suficiente para acompanhar atividades desta natureza, e se insurgir quando necessário.

A CF/88 ao atribuir à coletividade "o dever de defender e preservar o meio ambiente para as presentes e futuras gerações”, pressupõe que seus cidadãos tenham acesso a informações, como as repassadas nas publicações dos estudos ambientais, e em audiências públicas provenientes dos processos de licenciamentos aos empreendimentos potencialmente degradadores, de forma clara, precisa, compreensível. Entretanto, como se falar em transparência e precisão quando o Poder Público não se empenha em formar cidadãos com base técnica e crítica o suficiente para acompanhar discursos e documentos tão específicos como os apresentados nos espaços acima exemplificados, e em face deles se insurgir?

Neste enfoque, insiste-se pela necessidade de se vincular à Política Nacional de Educação Ambiental (PNEA), a previsão de disciplina específica na matriz curricular do ensino básico brasileiro, visando sedimentar de forma técnica e efetiva na formação dos cidadãos, os objetivos previstos no art. $5^{\circ}$ da Lei n. ${ }^{\circ}$ 9.795/99, haja vista que "pessoas educadas estão mais predispostas à participação, ao exercício de seus direitos voltados para a formação da vontade estatal, contribuindo com ideias e ações na resolução de questões de interesse público, como são as questões ambientais” (Carvalho \& Gomes, 2016, p. 21).

Levando em consideração todo o exposto e a inércia do Poder Público em efetivar em grau máximo o preceito constitucional da educação ambiental, como um dos meios a assegurar o direito fundamental ao meio ambiente ecologicamente equilibrado, sugere-se como solução o ajuizamento de um processo coletivo estrutural de interesse público, de modo a compelir o Estado, em sua competência legislativa, a alterar a Lei n. ${ }^{\circ}$ 9.795/99, bem como a Lei n. ${ }^{\circ}$ 9.394/96 de modo a incluir a obrigatoriedade de uma disciplina específica nas bases curriculares do ensino básico brasileiro, sendo, na mesma demanda, instado o Poder Público, em sua competência executiva, a implementar a disciplina em comento.

Neste ínterim, passa-se a demonstrar, ainda que de forma genérica, em quais termos o procedimento proposto se perfaria. 


\subsubsection{Polo ativo}

Ante a competência que lhe é atribuída pela $\mathrm{CF} / 88$, mais precisamente no art. 127, o Ministério Público seria o legitimado ativo, de modo a defender o regime democrático e o interesse social de se implementar a educação ambiental, como disciplina específica no ensino básico brasileiro, visando afastar a normatividade simbólica da EA e, de fato, instruir e capacitar a coletividade a garantir e resguardar o direito ao meio ambiente ecologicamente equilibrado.

\subsubsection{Polo passivo}

Figurando no polo passivo da demanda, o que não significa dizer estar-se sob a condição de resistência, mas sim de abertura, e cooperatividade para o alcance do objeto da lide estrutural de interesse público, estar-se-ia a União, enquanto Poder Público, constitucionalmente incumbido pelo $\S 1^{\circ}$ do art. 225, a promover a educação ambiental perseguida de forma ampla e efetiva.

Em litisconsorte necessário, o Ministério da Educação (MEC), também seria demandado, uma vez ser a autarquia federal responsável por executar as políticas públicas que tangenciam a temática educacional, prevista pelo art. 205 da CF/88. Sua legitimidade também se justifica, considerando que além da alteração da Lei n. ${ }^{\circ}$ 9.795/99 para incluir a educação ambiental como disciplina específica, a inclusão deverá ser feita na Lei n. ${ }^{\circ} 9.394 / 96$, para fins de uniformização, incluindo-a como disciplina específica obrigatória também nas diretrizes da educação nacional.

\subsubsection{Causas de pedir}

Como causa de pedir tem-se que o Poder Público ao regulamentar e implementar o preceito norteador constitucionalmente garantido da educação ambiental, o qual visa assegurar o direito fundamental do meio ambiente ecologicamente equilibrado, não pode minimizá-lo como feito na Lei n. 9.795/99, traduzindo o preceito em comento apenas de forma simbólica, ao afastar a previsão de uma matéria específica e obrigatória. Deve, entretanto, instituí-lo em grau máximo e latente.

Desta forma, levando em consideração a necessidade urgente de se repensar a importância da educação ambiental, como disciplina específica na matriz curricular do ensino básico brasileiro, de modo a capacitar a coletividade com conhecimento crítico e técnico o suficiente para exercer sua incumbência assecuratória ao meio ambiente em face daquilo e daqueles que por ventura o ameace ou danifique, pleitear-se-á por chamar o Poder Público ao feito, de modo a instá-lo a desempenhar-se para instituir e implementar a política pública em questão.

\subsubsection{Pedidos estratégicos de processo estrutural para solução da litigância de interesse público}

Ao pretender instar o Poder Público, a vincular na legislação e implementar a educação ambiental como disciplina específica obrigatória nas grades curriculares do ensino básico brasileiro, visando regular arranjos socioambientais futuros, os pedidos do procedimento em comento, deverão se figurar de forma própria e estratégica, ante o caráter público e estruturador do processo.

Dito isto, ao reclamar o funcionamento de uma política pública, cuja solução não será imposta e sim negociada, e sobre a qual estará o Poder Judiciário vinculado continuamente às fases de sua implementação, os legitimados ativos da demanda deverão pugnar por pedidos dinâmicos, não necessariamente líquidos e certos, mas sim amplos e prospectivos que repercutirão nas decisões, que fixarão, conforme reflete Neto (2019, p. 78), conteúdos gerais, princípios de ação “[...] das quais partirão em seguida os "projetos executivos" destinados à sua implementação".

Desta forma, é possível se vislumbrar pela elaboração de planos e cronogramas de ações, estabelecendo prazos e fases para que o Poder Público em suas múltiplas facetas se organize para instituir e alcançar as estipulações determinadas nas 
negociações processuais realizadas entre ele, os autores da demanda, bem como todos os terceiros interessados que poderão se manifestar.

À título de exemplo, sugere-se pedir, inicialmente, que seja o Poder Público em sua competência legislativa, instado a incluir na Lei n. ${ }^{\circ}$ 9.795/99, a previsão da educação ambiental, como disciplina específica na matriz curricular do ensino básico brasileiro, incluindo ainda a previsão, nas diretrizes de educação nacional, fixando um prazo para o feito. Em sequência, que apresente planos orçamentários para a implementação da política a ser adotada, bem como traga ao feito o estudo para formação, seleção e contratação de profissionais capacitados a ministrar a disciplina em comento, e ainda que apresente planejamento de escolhas de escolas pilotos, sejam públicas e/ou privadas, para implementação da política.

\subsubsection{Amicus Curiae}

Por fim, é possível prever a atuação de terceiros intervenientes no procedimento, como movimentos organizados da sociedade civil, experts no tema socioambiental, e demais atores para, figurando como amicus curiae, manifestarem nos autos, por meio de pareceres, bem como sustentações orais em audiência públicas, de modo a salientar a importância de se implementar a disciplina específica da Educação Ambiental nas bases curriculares do ensino básico nas escolas brasileiras, bem como vincularem proposições para a ocorrência desta implementação.

\section{Considerações Finais}

$\mathrm{O}$ art. 225 da CF/88 prevê o meio ambiente ecologicamente equilibrado como direito fundamental, bem de uso e interesse do povo, o qual em conjunto com o Poder Público deverá defendê-lo e preservá-lo para as presentes e futuras gerações. Como política norteadora a fim de equipar a coletividade com conhecimento técnico e crítico o suficiente para assegurar a efetividade desse direito a Carta Magna descreve de forma ampla e incisiva no $\S 1^{\circ}$, inc. VI do mesmo dispositivo supramencionado, ser a educação ambiental, uma incumbência do Estado, a ser promovida em todos os níveis de ensino. Entretanto, ao regulamentar tal preceito norteador, o Poder Público, ao contrário de legislar e implementá-lo em grau máximo, vem minimizando tal política a uma educação meramente simbólica e transversal.

Diante do cenário mundial de escassez de recursos naturais e voltando-se a nível brasileiro, dos constantes desastres/crimes ambientais, oriundos de interesses econômicos, empreendimentos predadores e de uma sociedade ainda inerte e pouco participativa nos temas e repercussões ambientais, faz-se necessário repensar na urgência de se vincular e instituir uma efetiva política pública de educação ambiental de modo a formar uma coletividade atenta e capacitada crítico-tecnicamente. Com tal formação, intenciona-se que a atuação dos cidadãos em prol do meio ambiente não se dará apenas em âmbito de seus cotidianos individuais, mas também no contexto de se insurgirem coletivamente em conjunto em face daquilo e daqueles que porventura atuem ou tenham interesses em atuar de modo a violar a ecologia equilibrada do meio ambiente, a qual é direito de todos.

Pelo raciocínio traçado, propõe-se que o processo estrutural de interesse público, se configura como um instrumento processual hábil para remediar a normatividade simbólica da educação ambiental, pois, ante à sua característica aberta, negociativa e prospectiva, se potencializa como mecanismo a instar o Poder Público, em sua competência legislativa e executiva, a vincular e implementar a educação ambiental como disciplina específica obrigatória no ensino básico brasileiro. Tal inclusão, seria uma das formas a solucionar os problemas de efetividade da educação ambiental, de modo a modificar os arranjos socioambientais futuros, como reflexo da formação de uma sociedade democrática, mais insurgente e consciente. Por fim, pontua-se que levando em conta a presente proposição de implementação da educação ambiental, os ora pesquisadores intencionam, em momento futuro, dar continuidade à presente pesquisa de modo a analisar a viabilidade de sua implantação na prática, considerando os desafios da atuação do poder público. 


\section{Agradecimentos}

Trabalho financiado pelo Edital no 02/2021 de Incentivo à Pesquisa da Escola Superior Dom Helder Câmara, resultante do Grupo de Pesquisa (CNPQ): Responsabilidade Civil e Processo Ambiental (RECIPRO).

\section{Referências}

Aguirre, L. E. de M. (2015). O constitucionalismo dirigente e a proteção do meio ambiente no mundo globalizado. Revista Direito à Sustentabilidade, 2, 59/73. http://saber.unioeste.br/index.php/direitoasustentabilidade/article/view/12352.

Antunes, P. de B. (2012). Direito ambiental. (14a ed.). Atlas.

Bonifácio, A. C., \& Santos, J. C. Y. S. dos. Mobilização coletiva e tutela jurisdicional do meio ambiente: principais desafios à luz da Constituição Federal de 1988. Revista Veredas do Direito, 17, 191/212. http://revista.domhelder.edu.br/index.php/veredas/article/view/1494.

Brasil. (1988). Constituição da República Federativa do Brasil. Centro Gráfico.

Brasil, Deilton R., Santos, Aline A. A. A., \& Paula, E. D’. de. (2016). Os mecanismos processuais garantidores da participação popular no âmbito do estado de direito ambiental. Revista Direito à Sustentabilidade, 2, 11/28. http://e-revista.unioeste.br/index.php/direitoas ustentabilidade/article/view/14649/9931.

Brasil. Lei nº 6.938, 31 de agosto de 1981. Dispõe sobre a Política Nacional do Meio Ambiente, seus fins e mecanismos de formulação e aplicação, e dá outras providências. Diário Oficial da União. http://www.planalto.gov.br/ccivil_03/LEIS/L6938.htm.

Brasil. Lei $\mathrm{n}^{\circ}$ 9.605, de 12 de fevereiro de 1998. Dispõe sobre as sanções penais e administrativas derivadas de condutas e atividades lesivas ao meio ambiente, e dá outras providências. Diário Oficial da União. http://www.planalto.gov.br/ccivil_03/leis/19605.htm.

Brasil. Lei no 9.795, de 27 de abril de 1999. Dispõe sobre a Educação Ambiental e institui a política nacional de educação e dá outras providências. Diário Oficial da União. http://www.planalto.gov.br/ccivil_03/leis/19795.htm.

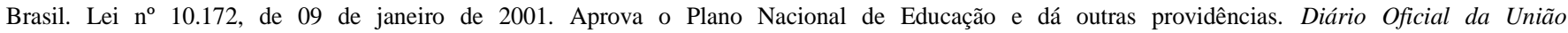
http://www.planalto.gov.br/ccivil_03/leis/leis_2001/110172.htm.

Brasil. (2012) Ministério da Educação. Conselho Nacional de Educação. Resolução CNE/CP n ${ }^{\circ} 2$, de 15 de junho de 2012 . Estabelece as Diretrizes Curriculares Nacionais para a Educação Ambiental. Diário Oficial da União.

Carvalho, Vânia A. de O., \& Reis, É. V. B. (2017). A necessidade da releitura da ação educativa presente na educação ambiental como pré-requisito ao alcance do meio ambiente ecologicamente equilibrado. Revista de Pesquisa e Educação Jurídica, 3, 22/43. https://www.indexlaw.org/index.php/rpej/article/view/2021.

Demoly, Karla R. do A., Santos, \& Joceilma S. B. dos. (2018). Aprendizagem, Educação Ambiental e Escola: Modos de Agir na Experiência de estudantes e professores. Revista Ambiente e Sociedade, 21 1/20. https://www.scielo.br/j/asoc/a/PDtkjHrq9jwWzYjnQW8YxVf/?lang=en.

Didier Jr., Fredie, Oliveira, Rafael A. de, \& Zaneti Jr, H. (2020). Elementos para uma teoria do processo estrutural aplicada ao processo civil brasileiro. Revista de Processo, 303, 45/81. https://www.academia.edu/42872474/elementos_para_uma_teoria_do_processo_estrutural_aplicada_ao_processo_civil_brasileiro.

Escorihuela, A., Hernández, Y., \& Juvinao, D. D. L. (2019). Una Encrucijada Gerencial: La Educacion Ambiental VS. Educacion para el Desarrollo Sostenible. Revista de Ciências Sociais, Humanas e Engenharia, 4, 231/246. http://publicacoes.uor.ed.ao/index.php/sapientiae/article/view/167.

Fiss, O. (1993). The allure of individualismo. Iowa Law Review, 78, 965/979, https://digitalcommons.law.yale.edu/cgi/viewc ontent.cgi? article=2307\&context=fss_papers\&httpsredir=1\&referer=.

Gil, A. C. (2009). Como elaborar projetos de pesquisa. (4. Ed.). Atlas.

Gomes, Magno F., \& Carvalho, Vânia A. de O. (2018). Educação Ambiental e sua Normatividade Simbólica. R. Jur. FA7, 15, 13/28. https://periodicos.uni7.edu.br/index.php/revistajuridica/article/view/254/476.

Gomes, M. F., \& Ferreira, L. J. (2017). A dimensão jurídico-política da sustentabilidade e o direito fundamental à razoável duração do procedimento. Revista do Direito, 52, 93/111. https://online.unisc.br/seer/index.php/direito/article/view/8864.

Gomes, M., \& Souza, J. C. (2020). Participação Popular na Gestão Transparente do Meio Ambiente: educação ambiental e direito à informação. R. Jur. FA7. 17, 1, 81/94. https://periodicos.uni7.edu.br/index.php/revistajuridica/article/view/909.

Instituto brasileiro de pesquisa e estatística. (2018). Pesquisa Nacional por Amostra de Domicílios Contínua. https://www.ibge.gov.br/estatisticas/sociais/populacao/9171-pesquisa-nacional-por-amostra-de-domicilios-continua-mensal.html?=\&t=downloads.

Linhares, M. T. M., \& Piemonte, M. N. (2010). Meio Ambiente e Educação Ambiental à Luz Do Princípio da Dignidade da Pessoa Humana. Revista Veredas do Direito, 7, 101/124. http://revista.domhelder.edu.br/index.php/veredas/article/view/192.

Neto, F. de B. e S. (2019). Breves considerações sobre os processos estruturais. Civil Procedure Review, 10, 75/88, https://www.jfpe.jus.br/images/stories/docs_pdf/biblioteca/artigos_periodicos/FranciscoAntoniodeBarroseSilvaNeto/breves_consideracoes_Civil_Proce dure_Review_2019.pdf. 
Research, Society and Development, v. 10, n. 15, e484101523033, 2021

(CC BY 4.0) | ISSN 2525-3409 | DOI: http://dx.doi.org/10.33448/rsd-v10i15.23033

Organização das nações unidas. (1992). Conferência das Nações Unidas sobre o Meio Ambiente e o desenvolvimento (CNUMAD). Agenda 21. https://www.mma.gov.br/responsabilidade-socioambiental/agenda-21.

Reis, A. P. D., \& Passamani, B. M. (2019). A responsabilidade penal da pessoa jurídica no atual contexto jurisprudencial dos crimes ambientais. Derecho y Cambio Social, 296/310. https://nx.derechoycambiosocial.com/ojs3.1.14/index.php/derechoycambiosocial/article/view/184/126.

Severino, J. A. (2007). Metodologia do trabalho cientifico. Cortez.

Silva, C. R. da. (2006). Metodologia da pesquisa aplicada à contabilidade: orientações de estudos, artigos, relatórios, monografias, dissertações e teses. Atlas.

Steinmetz, W. (2009). Educação ambiental, Constituição e Legislação: análise jurídica e avaliação crítica após dez anos de vigência da Lei 9.795/1999. Revista de Direito ambiental, 15, 189/202.

Verbic, F. (2013) Ejecucion de sentencias en litigios de reforma estructural en la República Argentina: Dificultades políticas y procedimentales que inciden sobre la eficacia de estas decisiones. In: XXVII Congresso Nacional de Derecho Procesal. https://www.academia.edu/4563 303/Ejecuci\%C3\%B3n_de_sentencia_en_litigios_de_reforma_estructural_Dificultades_pol\%C3\%ADticas_y_procedimentales_que_inciden_sobre_la_eficacia _de_estas_decisiones.

Vitorelli, E. (2018). Levando os conceitos a sério: processo estrutural, processo coletivo, processo estratégico e suas diferenças. Revista de Processo, 284, $12 / 13$.

Zaneti Jr., H. (2019). Ativismo da lei e da constituição na tutela coletiva brasileira: processos estruturais, processos complexos e litígios de difusão irradiada. In: Costa, F. V., Gomes, M. F., Nunes, D. (Org.). Processo Coletivo, Desenvolvimento Sustentável e Tutela Diferenciada dos Direitos Fundamentais. Editora Fi, Cap. 15, 407/428. 